\title{
The relationship between physical activity and lymphoma: a systematic review and meta analysis
}

\author{
Gwynivere A. Davies ${ }^{1 *} \mathbb{D}$, Christopher Strader ${ }^{2}$, Richa Chibbar $^{3}$, Stefania Papatheodorou ${ }^{4}$ and Adam A. Dmytriw ${ }^{5}$
}

\begin{abstract}
Background: The literature suggests an increased risk between anthropometrics including higher body mass index and lymphoma incidence; however, the association with physical activity remains unclear. A systematic review/meta-analysis was therefore performed to examine this association with physical activity (total, recreational or occupational).

Methods: PubMed, Web of Science and Embase were reviewed from inception to October 2019 identifying relevant observational studies. Non-Hodgkin lymphoma (NHL) including subtypes diffuse large B cell lymphoma, follicular lymphoma and chronic lymphocytic leukemia/small lymphocytic lymphoma, and Hodgkin lymphoma (HL) were analyzed. Included studies reported activity, lymphoma cases, effect size and variability measures, and were restricted to human subjects of any age. Data was pooled generating summary relative risk (RR) estimates with 95\% confidence intervals (Cl) using random-effects models with primary outcome of histologically confirmed incident lymphoma.
\end{abstract}

Results: One thousand four hundred studies were initially identified with 18 studies (nine cohort, nine casecontrol) included in final analysis. Comparing highest vs. lowest activity categories was protective for all lymphoma (RR $0.89,95 \% \mathrm{Cl}$ 0.81-0.98). Sensitivity analysis demonstrated effect persistence within case-control studies (RR 0.82, 95\% Cl 0.71-0.96), but not cohort studies (RR 0.95, 95\% Cl 0.84-1.07). Borderline protective effect was seen for NHL (RR $0.92,95 \% \mathrm{Cl} 0.84-1.00$ ), but not HL (RR $0.72,95 \% \mathrm{Cl} 0.50-1.04$ ). Analysis by NHL subtype or gender showed no effect. Dose response analysis demonstrated a protective effect $(p=0.034)$ with a 1\% risk reduction per 3 MET hours/week (RR 0.99, 95\% Cl 0.98-1.00).

Conclusions: Physical activity may have a protective effect against lymphoma development; further studies are required to generate recommendations regarding health policy.

Trial registration: This study was registered prospectively at PROSPERO: CRD42020156242.

Keywords: Lymphoma, Physical activity, Meta-analysis

\footnotetext{
*Correspondence: gwynivere.davies@gmail.com

'Department of Oncology, Juravinski Cancer Centre- Hamilton Health

Sciences, Hamilton, ON, Canada

Full list of author information is available at the end of the article
}

\section{$\triangle B M C$}

(c) The Author(s). 2020 Open Access This article is licensed under a Creative Commons Attribution 4.0 International License, which permits use, sharing, adaptation, distribution and reproduction in any medium or format, as long as you give appropriate credit to the original author(s) and the source, provide a link to the Creative Commons licence, and indicate if changes were made. The images or other third party material in this article are included in the article's Creative Commons licence, unless indicated otherwise in a credit line to the material. If material is not included in the article's Creative Commons licence and your intended use is not permitted by statutory regulation or exceeds the permitted use, you will need to obtain permission directly from the copyright holder. To view a copy of this licence, visit http://creativecommons.org/licenses/by/4.0/. The Creative Commons Public Domain Dedication waiver (http://creativecommons.org/publicdomain/zero/1.0/) applies to the data made available in this article, unless otherwise stated in a credit line to the data. 


\section{Background}

Lymphoma is a common malignancy, with non-Hodgkin lymphoma (NHL) incidence estimated at 19.6 per 100 , 000 people per year and a lifetime risk of $2.2 \%[1,2]$. By comparison, Hodgkin lymphoma (HL) is much less common with only 8110 new cases and 1000 deaths per year. The incidence for both types has been decreasing over the past decade, with a drop of 0.9 and $1.8 \%$ yearly for NHL and HL respectively [3]. While a reassuring trend, up to one-third of patients will still die from NHL within the first 5 years (5-year survival 72\%) [4].

In addition to new oncologic therapies, further research is needed to direct disease prevention, specifically modifiable risk factors, such as physical activity. Prior metaanalyses demonstrated a relationship between obesity and lymphoma incidence in a dose-dependent manner (obesity vs. overweight vs. normal weight) [5-7]; however, it remains unclear if there is an association between physical activity and lymphoma independent of body mass index (BMI) [8]. Additionally, BMI does not always reflect obesity or inactivity, therefore an alternate metric was considered. Studies have shown a reduction in the risk of development of colon, breast, and endometrial cancer with physical activity [9], whereas various studies in lung, prostate and ovarian cancer have been inconclusive [10]. Better understanding of the available evidence for lymphoma could inform discussions with patients and better guide health policy recommendations.

Compared to the costs of treatment [11], physical activity is not only cost-effective [12] but is also associated with increased life expectancy and additional health benefits, including reductions in heart disease, hypertension, and diabetes [13]. Unfortunately, adherence to weight loss strategies and caloric restriction is low [13]. Therefore, a demonstrated protective effect against lymphoma and other cancers, independent of weight loss or normal range BMI, could lead to a focus in public health policy on physical activity with downstream effects on overall incidence and survival. This could additionally result in positive health system economic impacts.

This meta-analysis expands on prior work $[5,10,14]$ by incorporating two case-control $[15,16]$ and two cohort studies [17, 18] with 1432 additional lymphoma cases that have since been published, increasing case sample size by approximately $12 \%$. In addition, within previous efforts [10] the outcome key words of "(lymphoma OR Hodgkin)" were likely satisfactory, however the exposure keywords may have missed studies examining specific forms of activity leading to incomplete evaluation which require further examination in subgroup or sensitivity analyses. Lastly, while the effect size in the original meta-analysis suggested a nonsignificant protective effect (pooled odds ratio $(\mathrm{OR})=0.90,95 \%$ confidence interval (CI): 0.79-1.02, $p=0.10)$ [10], the limited number of studies may have precluded definitive assessment because of inadequate power. A latter analyses demonstrated a protective effect [14], although serious methodological concerns exist regarding subjects being included multiple times to account for different forms of activity (occupational and recreational) within the same analysis.

The objective of this meta-analysis is to examine all existing evidence to determine if physical activity leads to a lower risk for developing lymphoma.

\section{Methods}

\section{Literature search}

Cohort and case-control studies that reported the level or amount of physical activity, either recreational, occupational or total, and incidence of lymphoma development were identified using Medline, Embase and Web of Science using the search terms included in Supplementary Table 1 on October 28, 2019. An updated search was completed on August 2, 2020, which is reflected in the included manuscript and figures. Abstracts were screened by two researchers (two groups- G.D. and A.D, C.S and R.C.) working independently to select for fulltext reading. In case of disagreement, discussion with all screening researchers ensued until consensus was reached. No restrictions on publication date were applied. Subsequently, two researchers (same groups) independently performed full-text reading of each article for final selection. Additionally, bibliographies of articles selected for full text review were examined for further studies to include.

\section{Study selection and assessment of quality}

Articles were considered eligible if they contained original data on physical activity and risk of lymphoma. Overall or all lymphoma included patients with both NHL and HL; further subgroup analyses was performed as detailed below and according to NHL subtype. Studies were reviewed to ensure no duplication of included patients. If multiple publications utilizing the same population were identified, the most recent and more detailed article was included. The nine-star Newcastle-Ottawa scale (NOS) was used to assess for quality given the observational nature of cohort and case-control studies. G.D. and A.D. independently assessed study quality and group discussion was utilized to resolve disagreements.

\section{Data extraction}

General study characteristics (such as author name, year of publication, number of patients and years of follow up (cohort) or number of cases and controls (case-control)) were collected along with subject characteristics and activity level exposure. Lymphoma was commonly identified through cancer registry linkage, though some 


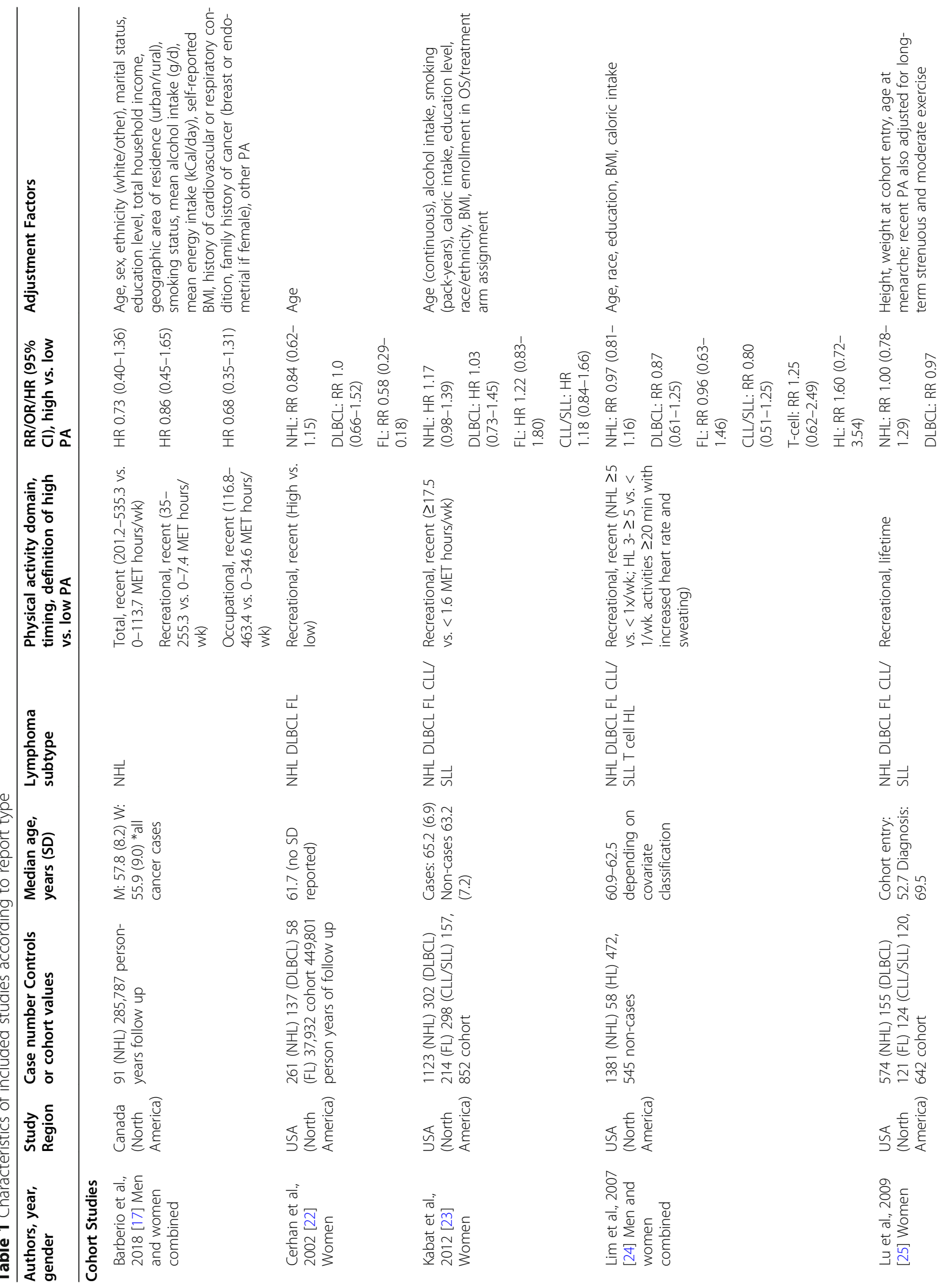




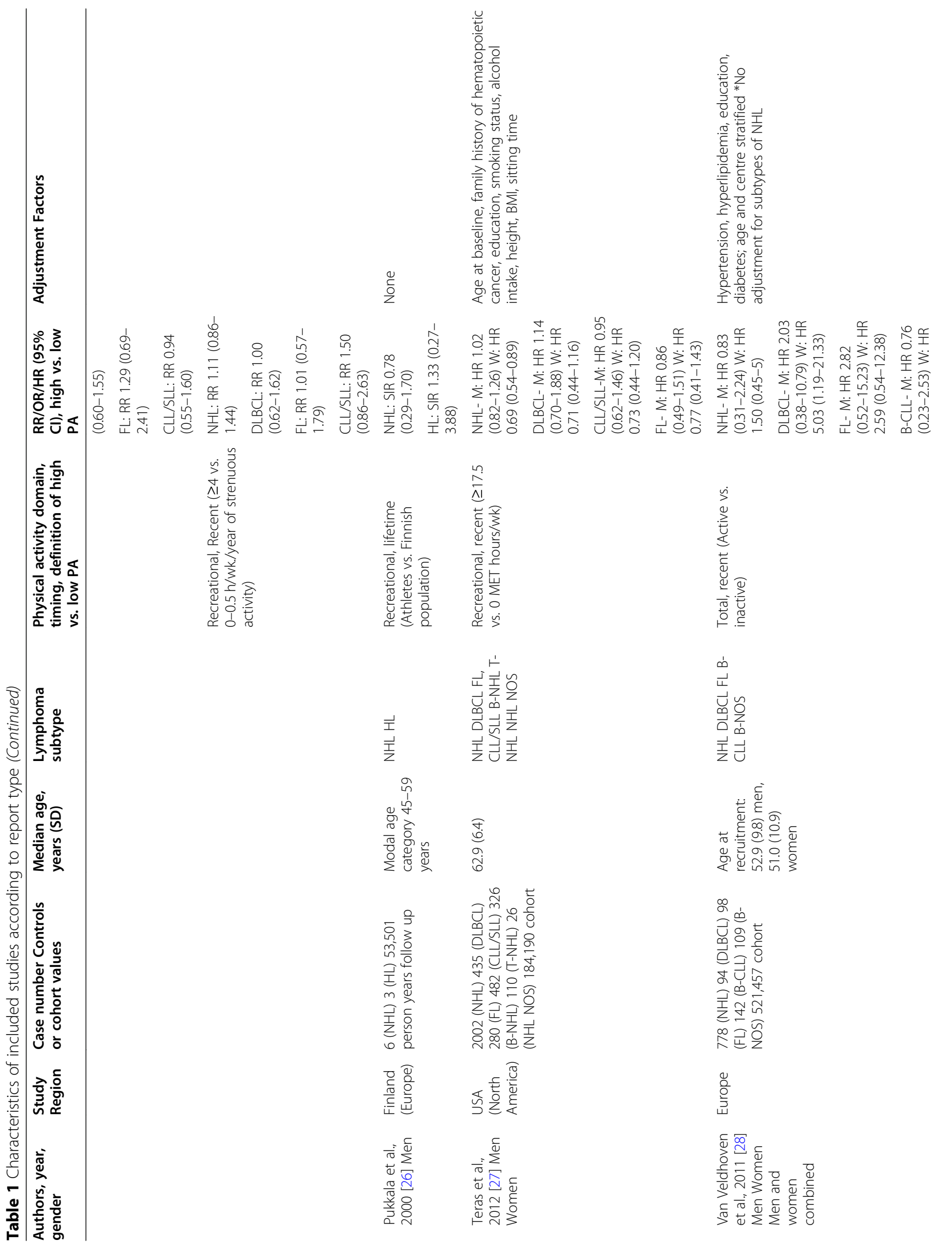




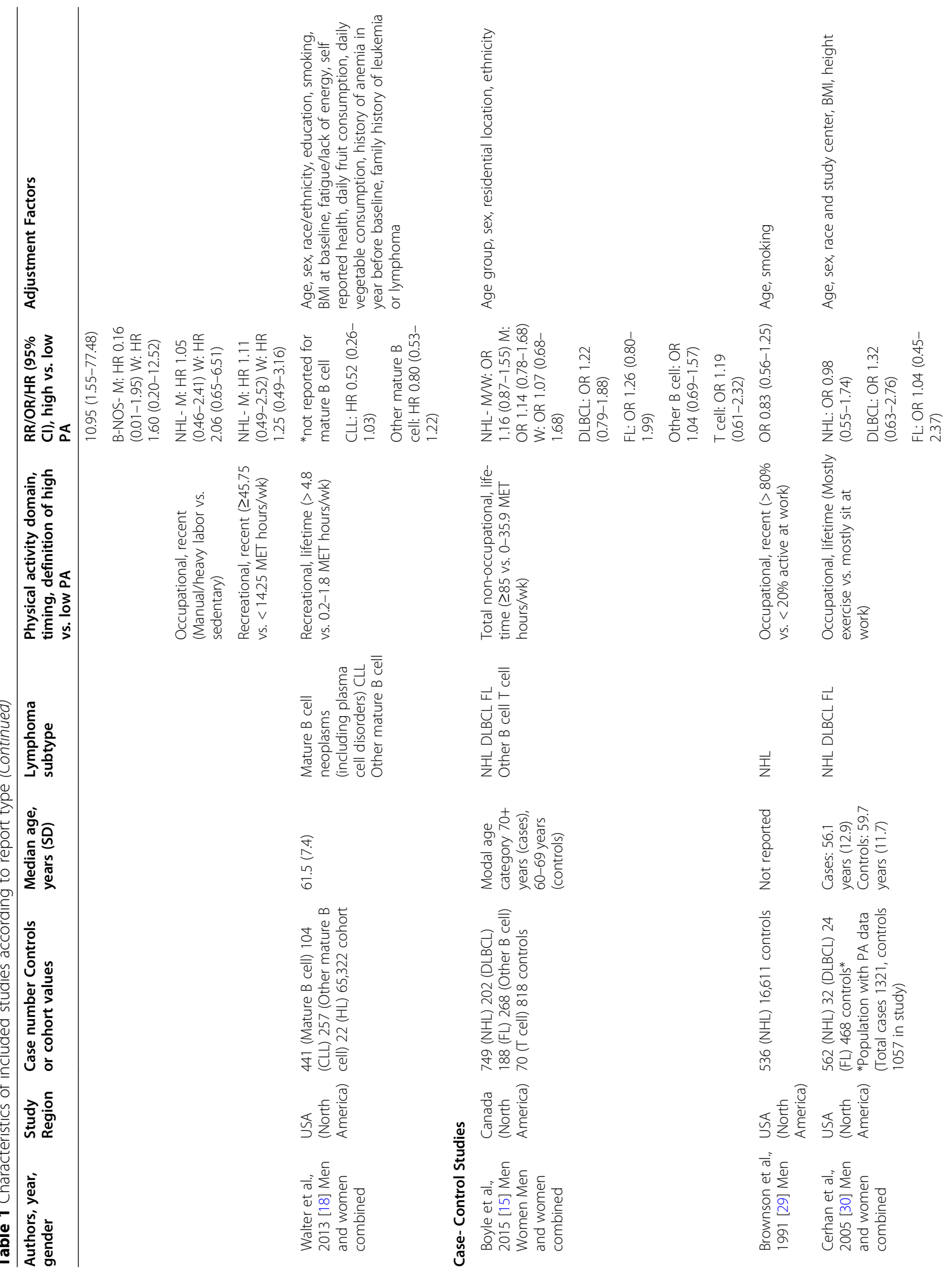




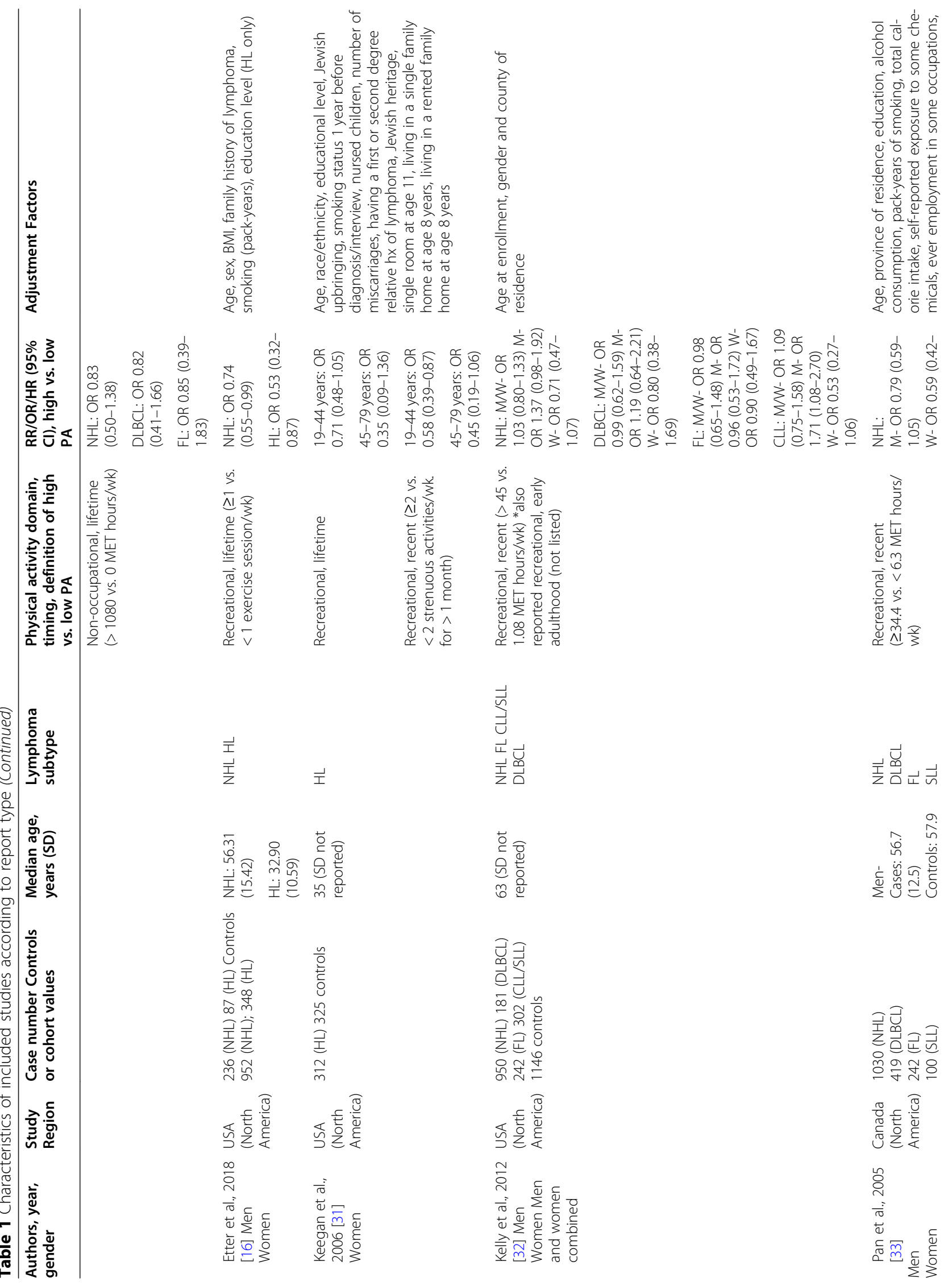




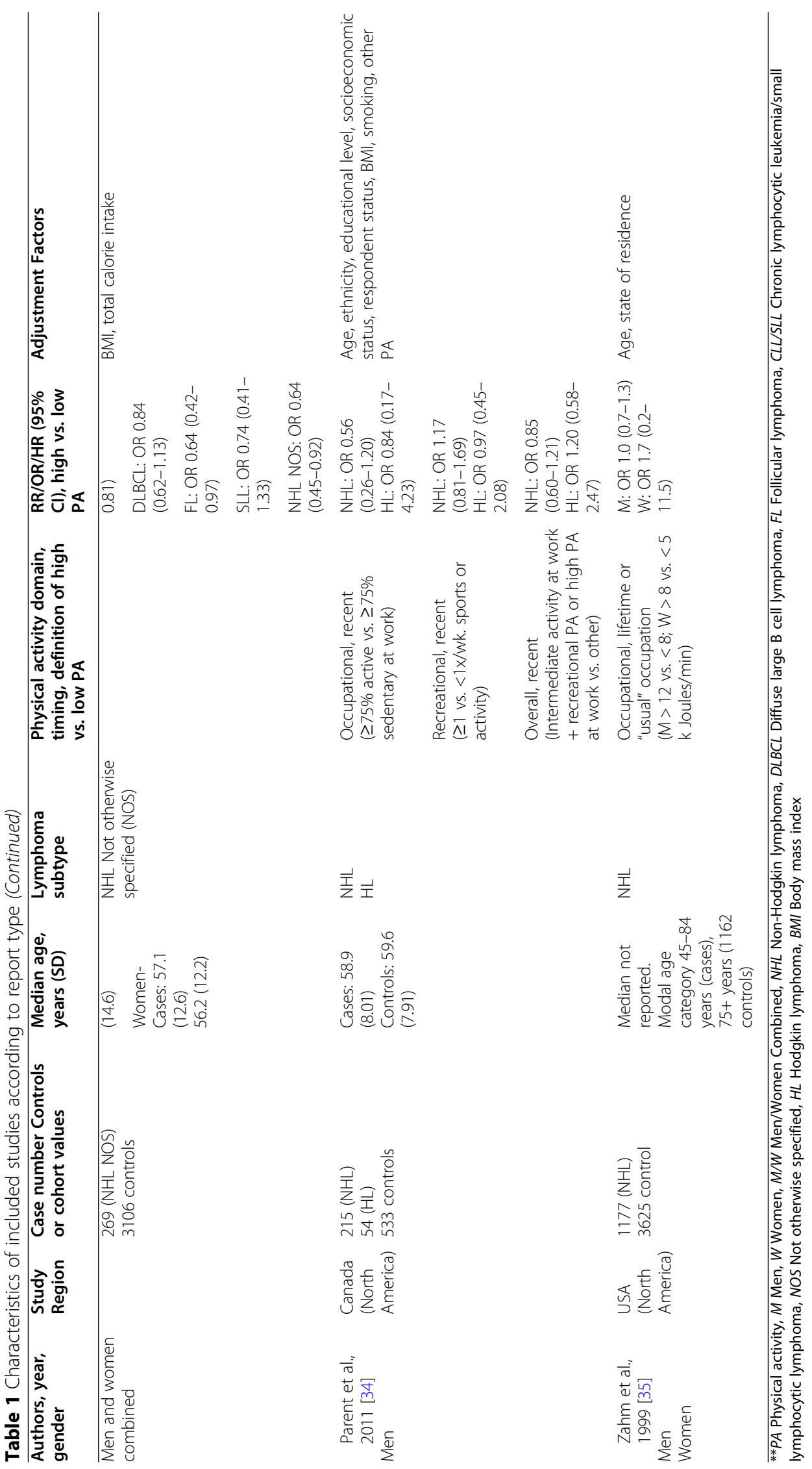


studies performed histologic review. As with previous analyses of physical activity and risk for lymphoma, the effect estimate used for pooled analysis compared the highest to lowest or referent physical activity level [10, 14]. In studies presenting multiple models including latency adjustment, only the risk and variability estimate from the maximally adjusted model were included.

\section{Statistical analyses}

Analysis was first conducted including patients from all studies, with risk estimates selected according to the most representative form of physical activity (total, recreational or if neither was available, occupational activity). Relative risk (RR) was chosen as the common measure; hazard ratios (HR) and OR were considered as $R R$ due to the low incidence of lymphoma. Summary estimation of risk was derived by random effects models with associated 95\% CI. Estimates were then pooled according to pre-specified subgroups, including: NHL vs. HL, type of physical activity (occupational vs. recreational), gender, and lymphoma subtype including follicular lymphoma (FL), diffuse large B cell lymphoma (DLBCL), and chronic lymphocytic leukemia/small lymphocytic lymphoma (CLL/SLL). Planned subgroup analysis that could not be completed included exposure reporting (self-reported vs. recorded) due to a lack of studies utilizing the latter method, location due to limited studies outside of North America, and age as this was generally included as a covariate. Study heterogeneity was analyzed using the Cochrane's Q test and the $\mathrm{I}^{2}$ statistic utilizing the following cut-offs: $<25 \%$ (low heterogeneity), 25-50\% (moderate heterogeneity), > 50\% (high heterogeneity). Begg's rank correlation and Egger's linear regression tests were used to examine for publication bias. Cumulative meta analysis assessed for change in effect size with time, especially as case definitions changed. Meta regression influence analysis was performed to assess for single study effects. Prediction intervals, demonstrating plausible ranges for the effect size in future studies, are included in Forest plots.

Dose response analysis utilized studies that reported metabolic equivalent of task (MET) hours/week of recreational physical activity (seven studies- four cohort, three case control). In studies where men and women were reported only separately, these were included as unique estimates. Midpoints of each range were used as the

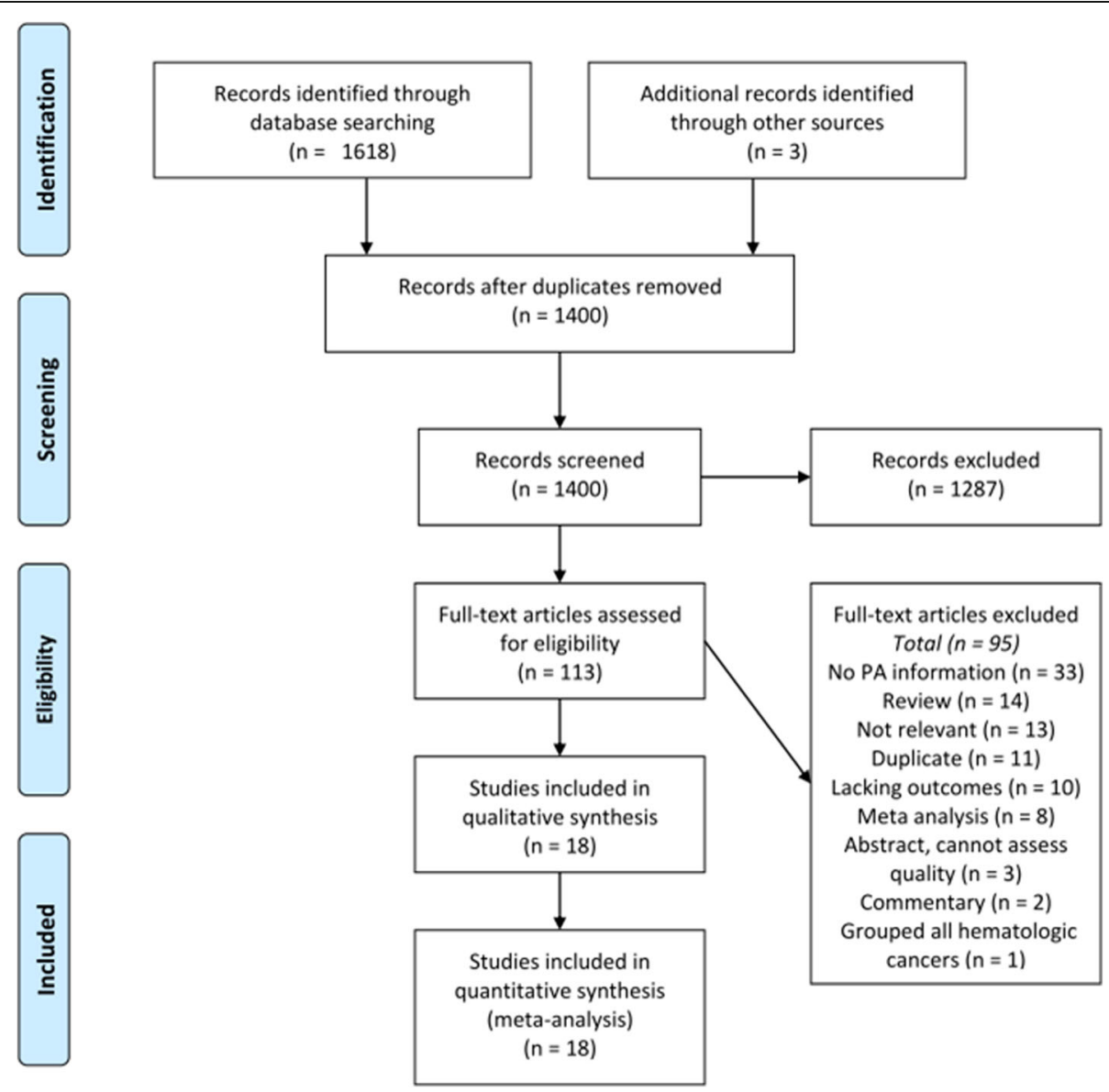

Fig. 1 PRISMA flow diagram 
corresponding "dose" and open ended categories utilized the lower end of the range multiplied by 1.2 as has been previously suggested $[19,20]$. Planned analyses were submitted to PROSPERO prior to data extraction. PRIS MA Checklist was followed and completed. All statistical analyses were performed using Stata version 15.1 (STATA Corp, College Station, TX, USA). $p$ values were two sided, and level of significance was set at $<0.05$.

\section{Results}

\section{Literature search and study characteristics}

Using our search strategy, 1400 potentially relevant studies were identified after removal of duplicates. After title and abstract screening, 113 studies were identified for full text review including those identified on review of prior meta-analyses $[10,14,21]$. Final analysis included 18 studies- 9 cohort $[17,18,22-28]$ and 9 case-control $[15,16,29-35]$, reporting a total of 12,053 new lymphoma cases. Study characteristics are summarized in Table 1. The PRISMA flowchart detailing study review is presented in Fig. 1; the most common reasons for exclusion were lack of physical activity information $(n=33)$, review or commentary $(n=16)$, not relevant $(n=12$, ie. physical activity levels after diagnosis of lymphoma), duplicate $(n=11)$, meta-analyses $(n=8)$, etc. Initially, the InterLymph studies were included, comprising a multinational consortium of NHL cases from 19 case-control studies presented as patient level data, however on close review of the datasets there was significant concern for patient overlap so they were excluded [36-39]. Additional review identified the Physical Activity Collaboration of the National Cancer Institute's Cohort Consortium, which pooled data from 12 prospective cohort studies comprising 1.44 million participants [40]. This evaluated leisure time physical activity and risk for cancer development in cohorts not specifically examining lymphoma development, identifying 6953 incident cases of NHL. However, four of these cohorts have already been included in our initial meta-analysis (accounting for 5643 cases); inclusion of risk estimates from the remaining cohorts (1310 new cases of NHL) did not change our risk estimate (RR 0.90 (0.83-0.98)) and as we were unable to assess quality of individual studies, these numbers/cohorts were not included in our final analysis. The overall pooled HR $0.91(0.83-1.00)$ is reassuringly similar to our identified risk estimate.

Publication years ranged from 1991 to 2018, and most studies were conducted in North America, with the exception of Pukkala et al. (2000) and van Veldhoven et al. (2011) $[26,28]$ conducted in Finland and multiple European countries respectively. Four studies reported only effect sizes for women [22, 23, 25, 31], three for men $[26,29,34]$, and three studies only presented both genders separately $[27,33,35]$. The remaining studies

Table 2 Quality assessment of included studies

\begin{tabular}{|c|c|c|c|c|c|}
\hline Study & Selection & Comparability & Outcome or Exposure & Total & Risk of Bias \\
\hline \multicolumn{6}{|l|}{ Cohort Studies } \\
\hline Barberio et al., 2018 [17] & $* * *$ & $* *$ & $* *$ & 7 & Low \\
\hline Cerhan et al., 2002 [22] & $* * *$ & * & ** & 6 & Moderate \\
\hline Kabat et al., 2012 [23] & $* * *$ & $* *$ & $* * *$ & 8 & Low \\
\hline Lim et al., 2007 [24] & $* * *$ & $* *$ & $* * *$ & 8 & Low \\
\hline Lu et al., 2009 [25] & $* *$ & * & ** & 5 & Moderate \\
\hline Pukkala et al., 2000 [26] & * & & $* *$ & 3 & High \\
\hline Teras et al., 2012 [27] & $* * *$ & $* *$ & $* * *$ & 8 & Low \\
\hline van Veldhoven et al., 2011 [28] & $* *$ & $*$ & * & 4 & Moderate \\
\hline Walter et al., 2013 [18] & $* * *$ & $* *$ & $* * *$ & 8 & Low \\
\hline \multicolumn{6}{|l|}{ Case-Control Studies } \\
\hline Boyle et al., 2015 [15] & $* * *$ & $* *$ & * & 6 & Moderate \\
\hline Brownson et al., 1991 [29] & * & * & * & 3 & High \\
\hline Cerhan et al., 2005 [30] & $* *$ & $* *$ & * & 5 & Moderate \\
\hline Etter et al., 2018 [16] & * & $* *$ & $* *$ & 5 & Moderate \\
\hline Keegan et al., 2006 [31] & $* * * *$ & $* *$ & * & 7 & Low \\
\hline Kelly et al., 2012 [32] & & $* *$ & $* *$ & 4 & Moderate \\
\hline Pan et al., 2005 [33] & $* * * *$ & $* *$ & $* *$ & 8 & Low \\
\hline Parent et al., 2011 [34] & $* *$ & $* *$ & * & 5 & Moderate \\
\hline Zahm et al., 1999 [35] & $* * *$ & * & * & 5 & Moderate \\
\hline
\end{tabular}


reported effect estimates for men and women combined +/- separately. Participants ranged from 19 to 84 years of age. Exposure (ie. type, intensity and frequency of activity) was most commonly self- reported by questionnaire, followed by phone and in person interview. Activity period ranged from "current" to lifetime, and four studies reported multiple types of physical activity (total, recreational or occupational) [17, 27, 28, 30]. There was wide variation in physical activity type (total, occupational, recreational) and reporting of activity level (days per week, percentage of time spent on strenuous activity, MET hours per week, etc).

Given the time periods included there were multiple lymphoma classification systems used. For instance, CLL was considered leukemia in the earlier studies, however was later combined with SLL under NHL in a WHO update, thus potentially biasing against an effect (less "lymphoma" cases in the initial studies). Adjustment for confounders varied widely across studies, with most adjusting for age, gender, and several for BMI, other types of activity, or other anthropometric measures. Studies ranged from high risk (three stars) to low risk of bias (eight stars), with the majority of case-control and cohort studies being of moderate (6/9) and low risk (5/ 9) of bias, respectively (Table 2).

\section{New cases of NHL and HL combined ("all lymphoma")}

In total, 3009 new cases of lymphoma were diagnosed within the highest physical activity level. This yielded 27 estimates comparing the highest to lowest level of physical activity, yielding a protective summary RR of 0.89 (95\% CI 0.81-0.98) (Fig. 2). The Q statistic indicates moderate heterogeneity of study results (chi2 $=49.39$; $\left.\mathrm{I}^{2}=47.4 \%, p=0.004\right)$. Use of Egger's test demonstrates

\section{All Lymphoma}

Study

ID

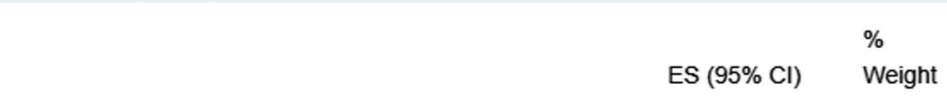

Barberio et al., 2018 (tot, NHL)

Boyle et al., 2015 (tot, NHL)

Brownson et al., 1991 (occ, NHL)

Cerhan et al., 2002 (rec, NHL)

Cerhan et al., 2005 (rec, NHL)

Etter et al., 2018 (rec, NHL)

Etter et al., 2018 (rec, HL)

Kabat et al., 2012 (rec, NHL)

Keegan et al., 2006 (rec, young, $\mathrm{HL}$ )

Keegan et al., 2006 (rec, older, HL)

Kelly et al., 2012 (rec, NHL)

Lim et al., 2007 (tot, NHL)

Lim et al., 2007 (tot, HL)

Lu et al., 2009 (rec, NHL)

Pan et al., 2005 (rec, NHL, F)

Pan et al., 2005 (rec, NHL, M)

Parent et al., 2011 (rec, NHL)

Parent et al., 2011 (rec, HL)

Pukkala et al., 2000 (rec, HL)

Pukkala et al., 2000 (rec, NHL)

Teras et al., 2012 (rec, NHL, M)

Teras et al., 2012 (rec, NHL, F)

van Veldhoven et al., 2011 (rec, NHL, M)

van Veldhoven et al., 2011 (rec, NHL, F)

Walter et al., 2013 (rec, NHL)

Zahm et al., 1999 (occ, NHL, F)

Zahm et al., 1999 (occ, NHL, M)

Overall (I-squared $=47.4 \%, p=0.004$ )

with estimated predictive interval

NOTE: Weights are from random effects analysis

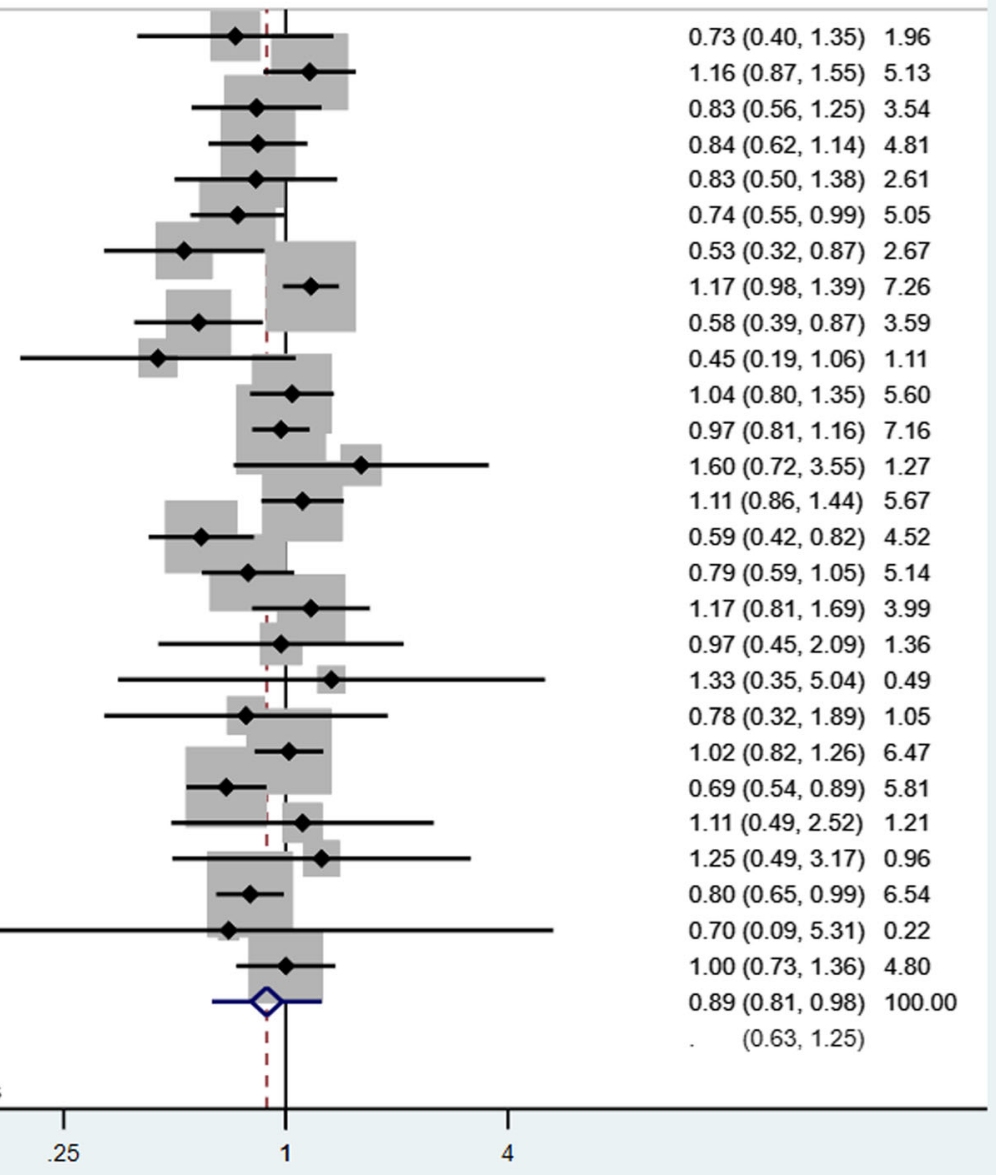

Fig. 2 Risk for all lymphoma comparing the highest versus lowest level of physical activity. ES = Effect size 
no small study effects $(p=0.29)$ and influence analysis excluding one study at a time shows slight variation in effect size, but this does not change by more than $2 \%$. The confidence intervals do not include 1 with exclusion of any studies. Sensitivity analysis utilizing cumulative meta-analysis demonstrates stabilization of effect size around 2009.

\section{Sensitivity analysis by study type}

Sensitivity analysis was performed by analyzing cohort and case-control studies separately assessing "all lymphoma". Among the nine cohort studies, 13 effect estimates were included as two studies described effect estimates separately by gender only and one study included both NHL and HL separately. The summary RR was not significant at 0.95 (95\% CI 0.84-1.07; $\mathrm{I}^{2}=39.9 \%$, $p=0.07$ ). By comparison, among the nine case-control studies, there were 14 effect estimates (both NHL and HL estimates from two studies, two studies with genders reported separately and one study with two individual age groups), and demonstrated significant protection with higher levels of exercise at RR 0.82 (95\% CI 0.71$\left.0.96 ; \mathrm{I}^{2}=49.5 \%, p=0.02\right)$.

\section{Subgroup analysis}

Seventeen of 18 studies examined the risk for NHL development in relation to physical activity. Pooling of effect size showed a marginally significant protective effect between the highest and lowest levels of physical activity (RR 0.92, 95\% CI 0.84-1.00, $\mathrm{I}^{2}=42.3 \%, \mathrm{p}=0.02$ ) seen in Fig. 3. No benefit was found in males with NHL (RR 1.02 , 95\% CI $0.90-1.15 ; \mathrm{I}^{2}=5.2 \%, p=0.39$ ), while in females there was a non-significant trend towards benefit (RR $0.88,95 \%$ CI $0.72-1.08 ; \mathrm{I}^{2}=66.2 \%, p=0.003$ ).

\section{All Studies \\ Non-Hodgkin Lymphoma}

Study

ID

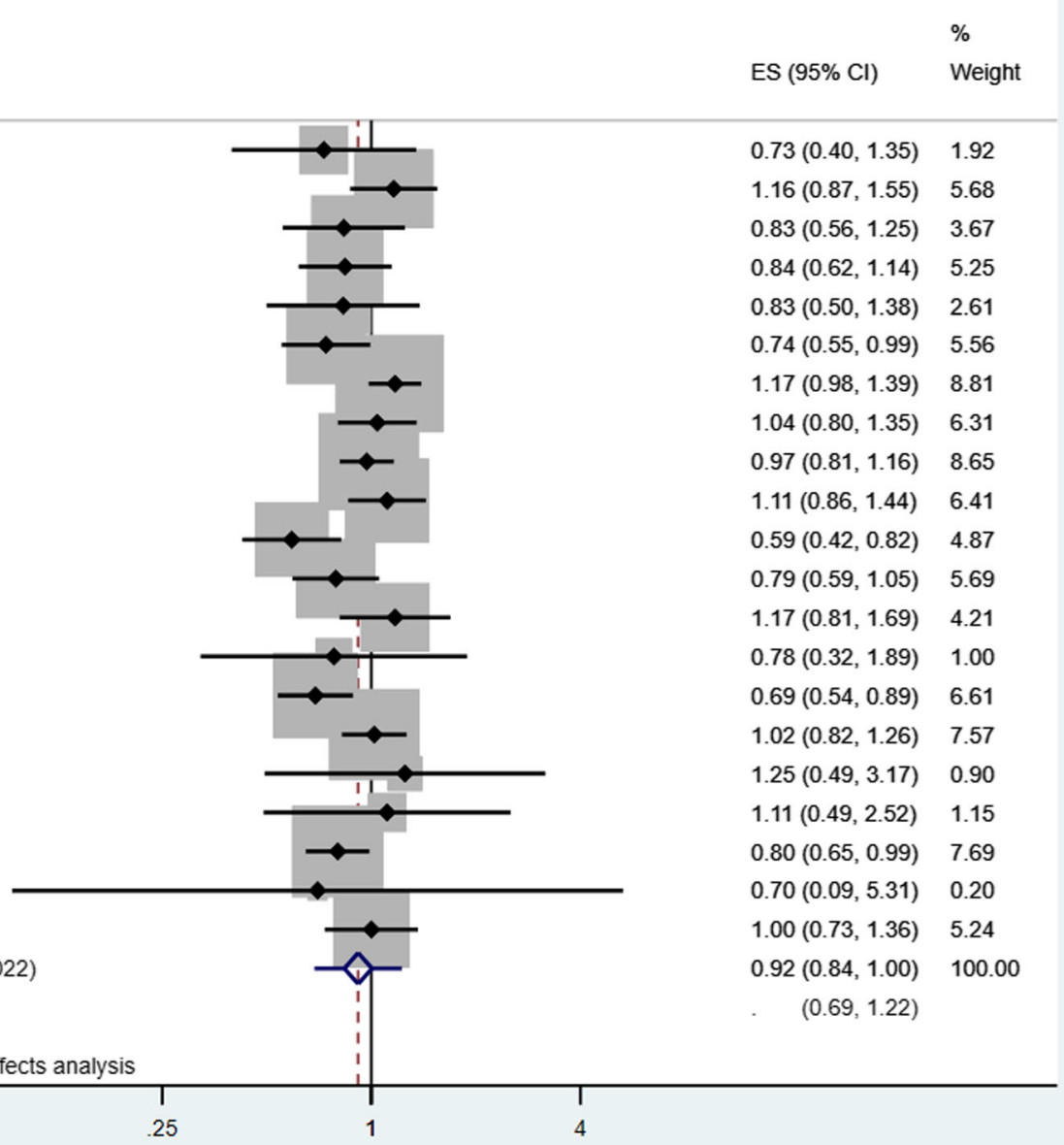

\begin{tabular}{|c|c|}
\hline ES $(95 \% \mathrm{Cl})$ & $\begin{array}{l}\% \\
\text { Weight }\end{array}$ \\
\hline $0.73(0.40,1.35)$ & 1.92 \\
\hline $1.16(0.87,1.55)$ & 5.68 \\
\hline $0.83(0.56,1.25)$ & 3.67 \\
\hline $0.84(0.62,1.14)$ & 5.25 \\
\hline $0.83(0.50,1.38)$ & 2.61 \\
\hline $0.74(0.55,0.99)$ & 5.56 \\
\hline $1.17(0.98,1.39)$ & 8.81 \\
\hline $1.04(0.80,1.35)$ & 6.31 \\
\hline $0.97(0.81,1.16)$ & 8.65 \\
\hline $1.11(0.86,1.44)$ & 6.41 \\
\hline $0.59(0.42,0.82)$ & 4.87 \\
\hline $0.79(0.59,1.05)$ & 5.69 \\
\hline $1.17(0.81,1.69)$ & 4.21 \\
\hline $0.78(0.32,1.89)$ & 1.00 \\
\hline $0.69(0.54,0.89)$ & 6.61 \\
\hline $1.02(0.82,1.26)$ & 7.57 \\
\hline $1.25(0.49,3.17)$ & 0.90 \\
\hline $1.11(0.49,2.52)$ & 1.15 \\
\hline $0.80(0.65,0.99)$ & 7.69 \\
\hline $0.70(0.09,5.31)$ & 0.20 \\
\hline $1.00(0.73,1.36)$ & 5.24 \\
\hline $0.92(0.84,1.00)$ & 100.00 \\
\hline$(0.69,1.22)$ & \\
\hline
\end{tabular}

Fig. 3 Risk for non-Hodgkin lymphoma comparing the highest versus lowest level of physical activity. ES = Effect size

Barberio et al., 2018 (tot)

Boyle et al., 2015 (tot)

Brownson et al., 1991 (ocC)

Cerhan et al., 2002 (rec)

Cerhan et al., 2005 (rec)

Etter et al., 2018 (rec)

Kabat et al., 2012 (rec)

Kelly et al., 2012 (rec)

Lim et al., 2007 (tot)

Lu et al., 2009 (rec)

Pan et al., 2005 (rec, F)

Pan et al., 2005 (rec, M)

Parent et al., 2011 (rec)

Pukkala et al., 2000 (rec)

Teras et al., 2012 (rec, F)

Teras et al., 2012 (rec, M)

van Veldhoven et al., 2011 (rec, F)

van Veldhoven et al., 2011 (rec, M)

Walter et al., 2013 (rec)

Zahm et al., 1999 (occ, F)

Zahm et al., 1999 (occ, M)

Overall (I-squared $=42.3 \%, p=0.022$ )

with estimated predictive interval

NOTE: Weights are from random effects analysis 
Interestingly, utilizing sex specific risk estimates significantly reduced between study heterogeneity as demonstrated by Cochrane's $\mathrm{Q}$ test (chi2 8.44) and $\mathrm{I}^{2}$ for men (see previous), but did not reduce heterogeneity for women, potentially suggesting differences in population selection.

Subgroup analysis by NHL subtypes of DLBCL, FL and CLL/SLL was performed to assess for biological heterogeneity in response to physical activity. In studies reporting DLBCL incidence, no difference in risk was found (RR 0.95, 95\% CI 0.83-1.09; $\mathrm{I}^{2}=0 \%, p=0.44$ ). This was consistent when restricting to estimates in men (RR 1.27, 95\% CI 0.71-2.27; $\mathrm{I}^{2}=0 \%, p=0.56$ ) or women (RR 0.97, 95\% CI 0.76-1.25; $\mathrm{I}^{2}=28.6 \%, p=0.22$ ).

Among those studies examining FL, no protective effect was found with physical activity (RR 0.95, 95\% CI $\left.0.80-1.12 ; \mathrm{I}^{2}=10.4 \%, p=0.34\right)$ in both genders, or when limited to men (RR 0.96, 95\% CI 0.65-1.43; $\mathrm{I}^{2}=0 \%, p=$ 0.42 ) or women (RR $0.97,95 \%$ CI $0.75-1.26 ; \mathrm{I}^{2}=9.3 \%$, $p=0.36)$ though sex stratified estimates were limited to only three and five studies, respectively.

Lastly, in studies assessing CLL/SLL incidence, there was no benefit between the highest and lowest levels of physical activity (RR 0.95, 95\% CI 0.76-1.20; $\mathrm{I}^{2}=43.6 \%$, $p=0.07$ ), or according to sex specific estimates for men (RR $1.18,95 \%$ CI $0.73-1.91 ; \mathrm{I}^{2}=49.9 \%, p=0.14$ ) or women (RR 1.07, 95\% CI $0.65-1.74 ; \mathrm{I}^{2}=70.1 \%, p=$ 0.010 , suggesting high heterogeneity).

In total, five studies reported HL incidence yielding six effect estimates (one study reported estimates for two separate age groups). There was a trend towards protective benefit comparing highest and lowest levels of physical activity (RR 0.72, 95\% CI 0.50-1.04; $\mathrm{I}^{2}=42.3 \%, p=$ 0.12 ) that was not significant (Fig. 4). A significant benefit was found in women (RR $0.55,95 \%$ CI $0.39-0.80$; $\left.\mathrm{I}^{2}=0 \%, p=0.60\right)$, but not men (RR 1.05 , 95\% CI $0.54-$ $\left.2.04 ; \mathrm{I}^{2}=0 \%, p=0.69\right)$.

Subgroup analysis of recreational versus occupational activity demonstrated a protective summary value (RR $0.85,95 \%$ CI $0.76-0.96 ; \mathrm{I}^{2}=53.3 \%, p=0.002$, high heterogeneity) for recreational PA; however, this was not seen for occupational activity (RR 0.93 , 95\% CI $0.76-$ $\left.1.14, \mathrm{I}^{2}=0 \%, p=0.75\right)$. Total activity level was not analyzed separately as this is generally a composite of the prior two measures.

\section{Dose response analysis}

Exploratory dose response analysis was performed utilizing the seven studies which reported MET hours/week of recreational physical activity and effect estimates. Most studies reported tertiles or quartiles of physical activity, and upper levels ranged from $>4.8$ MET hours/ week to $\geq 45.75$ MET hours/week, highlighting the differences in activity capture and populations. Dose response comprised 6019 newly diagnosed lymphoma cases and demonstrated a significant protective effect $(p=0.03$, Fig. 5), estimated as a $1 \%$ reduction in lymphoma incidence per $3 \mathrm{MET}$ hours/week of activity (RR 0.99, 95\% CI 0.98-1.00; $\mathrm{I}^{2}=61.4 \%, p=0.0003$ ).

\section{Discussion}

The aim of the current meta-analysis was to present an updated review of the literature on the association between physical activity and risk of lymphoma, and to address limitations of previous meta-analyses.

We demonstrate that high physical activity levels have a significant protective effect for the overall risk of lymphoma development, borderline protective effect for NHL, and no effect on HL incidence in both genders combined, though women alone had a reduced risk of lymphoma within the highest level of physical activity. This effect estimate is consistent with previous studies by Vermaete et al. (2013) demonstrating a pooled RR of 0.90 (95\% CI 0.79-1.02) and Jochem et al. (2014) with a significant pooled RR of 0.90 (95\% CI 0.81-0.99) for lymphoma development $[10,14]$. This suggests stabilization of effect with time as multiple newer studies were included in this updated analysis. Physical activity is postulated to reduce risk of other malignancies [41-44] through a variety of mechanisms that may be relevant to clonal lymphocyte dysregulation. These can include: epigenetic modification, such as via restoration of normal methylation status or upregulation of p53 proteins [45]; improved insulin sensitivity with resistance identified as a mediator between increased height or weight and lymphoma risk [21]; reduction of inflammatory cytokines via obesity reduction and lower levels of the ASC protein [45]; and various other biologic etiologies.

Sensitivity analysis demonstrated a non-significant effect in cohort studies, which would have a lower risk of bias due to their prospective design. This is relevant for physical activity, as there is potential for recall bias in selfreported recreational exercise, especially when considering lifetime values. However, this may be less relevant for occupational activity which was usually expertly coded according to an occupation algorithm. Another potential source of bias is reverse causation whereby those reporting lower baseline activity may paradoxically have an undiagnosed cancer. Multiple cohorts addressed this by performing "latency adjusted" analysis, in which cases diagnosed within the first 2 years of study were excluded without significant change in their estimates [17, 23, 25].

No noticeable difference in effect size was seen by NHL subtype, and the small number of further gender stratified studies limits specific conclusions. Several studies reported effect estimates for other NHL subtypes, such as mycosis fungoides/Sezary syndrome, marginal zone lymphoma, 


\section{All Studies \\ Hodgkin Lymphoma}

Study

ID
ES $(95 \% \mathrm{Cl}) \quad$ Weight

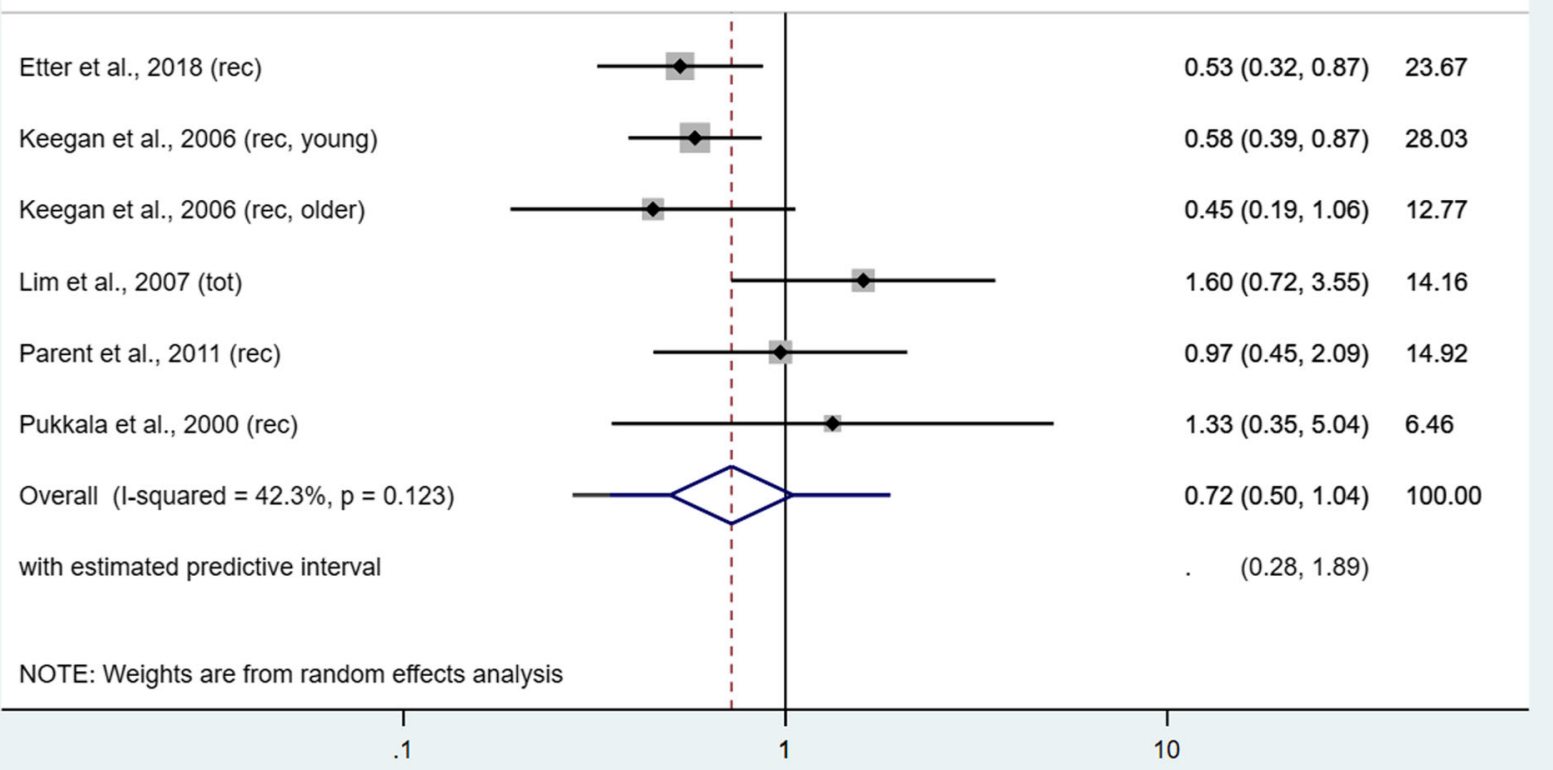

Fig. 4 Risk for Hodgkin lymphoma comparing the highest versus lowest level of physical activity. ES = Effect size

peripheral T cell lymphoma, and lymphoplasmacytic lymphoma/Waldenstrom macroglobulinemia, but were too infrequent to synthesize. The latency of lymphoma may be important to consider when deciding on relevant time period of activity. For example, recent BMI has significantly more impact on DLBCL than FL or CLL/SLL [21], which may relate to the longer period of development for indolent lymphomas. Analogously, lifelong activity may be more relevant to these lymphomas, whereas recent activity may have a stronger impact on aggressive lymphoma subtypes. This could be
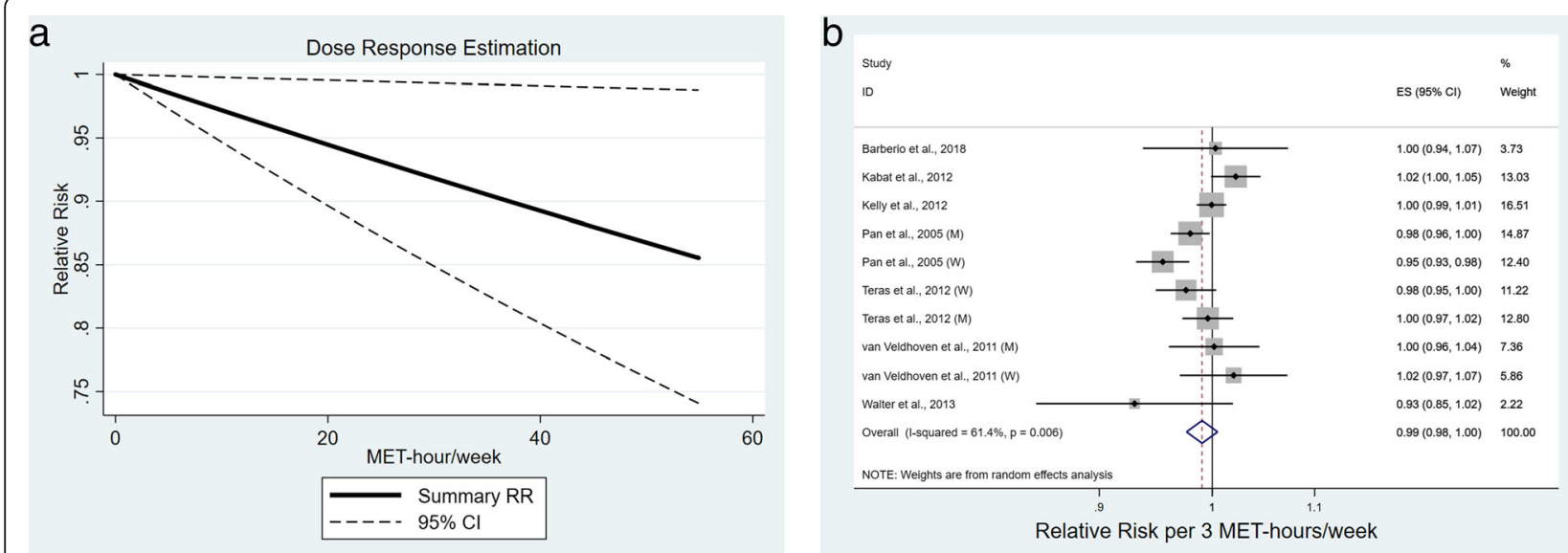

Fig. 5 Exploratory dose response analysis for studies reporting recreational physical activity in metabolic equivalent of task (MET) hours per week (a), and Forest plot demonstrating summary reduced relative risk per 3 MET hours per week (b) 
explored in future studies comparing lifelong and recent activity to NHL subtype incidence.

In examining gender modification, we included only studies that reported effect estimates for men or women alone. No protective effect of physical activity was seen for men, however in women there was reduced risk for HL and a protective trend for NHL. The biologic mechanisms for this effect are not fully understood, however most lymphomas are more common in males, thus development may be more heavily influenced by other biologic factors within this gender [37]. Previous authors have suggested this may also be due to estrogen or reproductive effects [14]- potentially by reducing body fat and thus the location of conversion from androstenedione to estrogen or by increasing levels of sex hormone binding globulin [6], which may affect inflammatory cytokine production. These results should be interpreted with caution, given the limited number of studies with sex stratification, although this was frequently controlled for in multivariable risk analysis.

Biologic plausibility is supported by the findings of reduced risk for lymphoma development by increasing MET hours/week of recreational physical activity. This occurred linearly with a reduction of $1 \%$ per 3 MET hours/week, equivalent to 1 hour of walking at average pace. Dose response has been demonstrated in other malignancies such as breast cancer [46] and represents an important step towards developing guidelines for activity. The World Health Organization recommends 150 min of moderate (3-6 MET/hour) level physical activity per week for adults, which translates to an average of 11.25 additional MET hours in addition to daily activities [47]. Using our estimated reduction of $1 \%$ per 3 MET hours/week, this could result in a relative 3.75\% fewer cases of lymphoma with guideline adherence.

Several limitations deserve discussion, primarily the heterogeneity in physical activity reporting. Some studies consider total activity, combining occupational, recreational and occasionally household activities, while others report only occupational or recreational activity, with widely discrepant referent and "highest level" of physical activity. As described previously, the upper quartile of MET hours/week of physical activity could vary by up to 10 between studies, ranging from $>4.8$ [18] to $\geq 45$ [32]. Ideally, patient level data would be accessed such that risk could be considered continuously rather than by quartile, however this is impractical given how initial data were collected (written questionnaire, etc) especially given variation in activity "units". Considerations for future analysis include collapsing all levels of physical activity for comparison to basal inactivity, similar to a meta-analysis examining cancer risk related to pickled vegetable consumption [48].
Additionally, the timing of activity varied greatly with studies reporting "baseline" activity at enrollment, personal quantification of lifetime activity, specific age activity, and so on. Given the overall incidence of lymphoma and non-compliance inherent to activity interventions [13], a randomized study examining this association is impractical; thus, health care policy recommendations will undoubtedly rely on observational studies. Standardization of timing, type and intensity of physical activity within future cohort studies is therefore imperative.

A further weakness includes the type and number of confounders adjusted for. While most studies adjusted for age, the number of included covariates ranged from zero to 12, demonstrating the wide variance in suspected etiologic triggers which was corroborated by the InterLymph consortium [37]. A recent meta-analysis demonstrated a positive association of early adult BMI and weight with NHL risk [21], and the complex interplay between BMI and physical activity was not consistently captured. Control selection in case-control studies is of particular importance, and one study utilized male patients with other cancers which could bias towards the null [29]. Gender stratified analyses were limited, especially for NHL subtypes and preclude definitive conclusions. Additionally, definitions of lymphoma have significantly changed in the past two decades with introduction of the WHO classification in the early 2000s, and therefore there is likely misclassification in older studies.

\section{Conclusions}

Overall, the highest level of physical activity appears to be protective against lymphoma development, compared to the lowest level. While this association is most apparent for NHL, a paucity of studies have assessed HL outcomes likely due to the lower incidence of this malignancy, and thus conclusions are limited. Female subjects appear to benefit from higher levels of activity however the limited number of gender stratified results preclude sex specific conclusions. Dose response analysis supports these conclusions, with a linear decrease in incidence seen with increasing recreational physical activity. This is especially relevant as recreational activity is more modifiable than occupation associated activity. Our study represents a comprehensive review of current literature without significant methodological concerns seen in previous analyses examining this relationship. Further higher quality cohorts, controlling for both anthropometric and cancer risk factors and with standardized activity reporting are needed to reach definitive conclusions and develop policy recommendations. 


\section{Supplementary information}

Supplementary information accompanies this paper at https://doi.org/10. 1186/s12885-020-07431-x.

\section{Additional file 1.}

\section{Abbreviations}

NHL: Non-Hodgkin lymphoma; HL: Hodgkin lymphoma; RR: Relative risk; $\mathrm{Cl}$ : Confidence intervals; BMl: Body mass index; OR: Odds ratio; NOS: Newcastle-Ottawa scale; HR: Hazard ratio; DLBCL: Diffuse large B cell lymphoma; FL: Follicular lymphoma; CLL/SLL: Chronic lymphocytic leukemia/ small lymphocytic lymphoma; MET: Metabolic equivalent of task

\section{Acknowledgements}

Dr. Paul Bain for assistance with developing the search strategy.

\section{Authors' contributions}

GD, CS, RC, AD performed article review, data extraction and synthesis. SP provided statistical support and overview. All authors contributed to writing the manuscript. All authors read and approved the final manuscript.

\section{Authors' information}

Not applicable.

\section{Funding}

Not applicable.

\section{Availability of data and materials}

All data generated or analysed during the study are included in this published article [and its supplementary information files].

\section{Ethics approval and consent to participate}

Not applicable.

\section{Consent for publication}

Not applicable.

\section{Competing interests}

The authors declare that they have no competing interests.

\section{Author details}

${ }^{1}$ Department of Oncology, Juravinski Cancer Centre- Hamilton Health Sciences, Hamilton, ON, Canada. ${ }^{2}$ Department of Surgery, University of Massachusetts Medical Center, Worchester, MA, Canada. ${ }^{3}$ Digestive Disease Center, Beth Israel Lahey Health, Harvard Medical School, Boston, MA, USA. ${ }^{4}$ Department of Epidemiology, Harvard T.H. Chan School of Public Health, Boston, MA, USA. ${ }^{5}$ Department of Medical Imaging, University of Toronto, Toronto, ON, Canada.

Received: 10 June 2020 Accepted: 16 September 2020

Published online: 06 October 2020

\section{References}

1. @NCICancerStats. Fact Sheets and Brochures - SEER: @NCICancerStats; 2019 [Available from: https://seer.cancer.gov/about/factsheets/index.html.

2. Ferlay J, Shin HR, Bray F, Forman D, Mathers C, Parkin DM. Estimates of worldwide burden of cancer in 2008: GLOBOCAN 2008. Int J Cancer. 2010; 127(12):2893-917

3. CdctobaccoFree. Extinguishing the Tobacco Epidemic in Missouri. Centers for Disease Control and Prevention. 2019.

4. Stephens DM, Li H, LeBlanc ML, Puvvada SD, Persky D, Friedberg JW, et al Continued risk of relapse independent of treatment modality in limitedstage diffuse large B-cell lymphoma: final and Long-term analysis of southwest oncology group study S8736. J Clin Oncol. 2016;34(25):29973004.

5. Psaltopoulou T, Sergentanis TN, Ntanasis-Stathopoulos I, Tzanninis I-G, Riza E, Dimopoulos MA. Anthropometric characteristics, physical activity and risk of hematological malignancies: a systematic review and meta-analysis of cohort studies. Int J Cancer. 2019;145(2):347-59.
6. Lichtman MA. Obesity and the risk for a hematological malignancy: leukemia, lymphoma, or myeloma. Oncologist. 2010;15(10):1083-101.

7. Bassig BA, Lan Q, Rothman N, Zhang Y, Zheng T. Current understanding of lifestyle and environmental factors and risk of non-hodgkin lymphoma: an epidemiological update. J Cancer Epidemiol. 2012;2012:978930.

8. Skibola CF. Obesity, diet and risk of non-Hodgkin lymphoma. Cancer Epidemiol Biomark Prev. 2007;16(3):392-5.

9. Clague J, Bernstein L. Physical activity and cancer. Curr Oncol Rep. 2012; 14(6):550-8

10. Vermaete NVH, Wolter P, Verhoef GEG, Kollen BJ, Kwakkel G, Schepers L, et al. Physical activity and risk of lymphoma: a Meta-analysis. Cancer Epidemiol Biomark Prev. 2013;22(7):1173-84.

11. Goldstein DA, Stemmer SM, Gordon N. The cost and value of cancer drugs are new innovations outpacing our ability to pay? Isr J Health Policy Res. 2016:5:40

12. Kutikova L, Bowman L, Chang S, Long SR, Arning M, Crown WH. Medical costs associated with non-Hodgkin's lymphoma in the United States during the first two years of treatment. Leuk Lymphoma. 2006;47(8):1535-44.

13. Warburton DER, Nicol CW, Bredin SSD. Health benefits of physical activity: the evidence. CMAJ. 2006;174(6):801-9.

14. Jochem C, Leitzmann MF, Keimling M, Schmid D, Behrens G. Physical activity in relation to risk of hematologic cancers: a systematic review and meta-analysis. Cancer Epidemiol Biomark Prev. 2014;23(5):833-46.

15. Boyle T, Gallagher RP, Gascoyne RD, Connors JM, Le ND, Spinelli JJ. Lifetime physical activity and the risk of non-Hodgkin lymphoma. Cancer Epidemiol Biomark Prev. 2015;24(5):873-7.

16. Etter JL, Cannioto R, Soh KT, Alquassim E, Almohanna H, Dunbar Z, et al. Lifetime physical inactivity is associated with increased risk for Hodgkin and non-Hodgkin lymphoma: a case-control study. Leuk Res. 2018;69:7-11.

17. Barberio AM, Friedenreich CM, Lynch BM, Campbell KL, Arora P, Brenner DR. Physical activity and Cancer incidence in Alberta's tomorrow project: results from a prospective cohort of 26,538 participants. Cancer Epidemiol Biomark Prev. 2018;27(8):945-54.

18. Walter RB, Buckley SA, White E. Regular recreational physical activity and risk of hematologic malignancies: results from the prospective VITamins and lifestyle (VITAL) study. Ann Oncol. 2013;24(5):1370-7.

19. Berlin JA, Longnecker MP, Greenland S. Meta-analysis of epidemiologic dose-response data. Epidemiology. 1993:4(3):218-28.

20. Rota M, Bellocco R, Scotti L, Tramacere I, Jenab M, Corrao G, et al. Randomeffects meta-regression models for studying nonlinear dose-response relationship, with an application to alcohol and esophageal squamous cell carcinoma. Stat Med. 2010;29(26):2679-87.

21. Hidayat K, Li H-J, Shi B-M. Anthropometric factors and non-Hodgkin's lymphoma risk: systematic review and meta-analysis of prospective studies. Crit Rev Oncol Hematol. 2018;129:113-23.

22. Cerhan JR, Janney CA, Vachon CM, Habermann TM, Kay NE, Potter JD, et al. Anthropometric characteristics, physical activity, and risk of non-Hodgkin's lymphoma subtypes and B-cell chronic lymphocytic leukemia: a prospective study. Am J Epidemiol. 2002:156(6):527-35.

23. Kabat GC, Kim MY, Jean Wactawski W, Bea JW, Edlefsen KL, AdamsCampbell LL, et al. Anthropometric factors, physical activity, and risk of nonHodgkin's lymphoma in the Women's Health Initiative. Cancer Epidemiol. 2012;36(1):52-9.

24. Lim U, Morton LM, Subar AF, Baris D, Stolzenberg-Solomon R, Leitzmann M, et al. Alcohol, smoking, and body size in relation to incident Hodgkin's and non-Hodgkin's lymphoma risk. Am J Epidemiol. 2007;166(6):697-708.

25. Lu Y, Prescott J, Sullivan-Halley J, Henderson KD, Ma H, Chang ET, et al. Body size, recreational physical activity, and B-cell non-Hodgkin lymphoma risk among women in the California teachers study. Am J Epidemiol. 2009;170(10):1231-40.

26. Pukkala E, Kaprio J, Koskenvuo M, Kujala U, Sarna S. Cancer incidence among Finnish world class male athletes. Int J Sports Med. 2000;21(3):216-20.

27. Teras LR, Gapstur SM, Diver WR, Birmann BM, Patel AV. Recreational physical activity, leisure sitting time and risk of non-Hodgkin lymphoid neoplasms in the American Cancer Society Cancer prevention study II cohort. Int J Cancer. 2012;131(8):1912-20.

28. van Veldhoven CM, Khan AE, Teucher B, Rohrmann S, Raaschou-Nielsen O, Tjonneland A, et al. Physical activity and lymphoid neoplasms in the European prospective investigation into Cancer and nutrition (EPIC). Eur J Cancer. 2011;47(5):748-60

29. Brownson RC, Chang JC, Davis JR, Smith CA. Physical activity on the job and cancer in Missouri. Am J Public Health. 1991;81(5):639-42. 
30. Cerhan JR, Bernstein L, Severson RK, Davis S, Colt JS, Blair A, et al. Anthropometrics, physical activity, related medical conditions, and the risk of non-hodgkin lymphoma. Cancer Causes Control. 2005;16(10):1203-14.

31. Keegan THM, Glaser SL, Clarke CA, Dorfman RF, Mann RB, DiGiuseppe JA, et al. Body size, physical activity, and risk of Hodgkin's lymphoma in women. Cancer Epidemiol Biomark Prev. 2006;15(6):1095-101.

32. Kelly JL, Fredericksen ZS, Liebow M, Shanafelt TD, Thompson CA, Call TG, et al. The association between early life and adult body mass index and physical activity with risk of non-Hodgkin lymphoma: impact of gender. Ann Epidemiol. 2012;22(12):855-62.

33. Pan SY, Mao Y, Ugnat AM. Physical activity, obesity, energy intake, and the risk of non-Hodgkin's lymphoma: a population-based case-control study. Am J Epidemiol. 2005;162(12):1162-73.

34. Parent MT, Rousseau MC, El-Zein M, Latreille B, Désy M, Siemiatycki J. Occupational and recreational physical activity during adult life and the risk of cancer among men. Cancer Epidemiol. 2011;35(2):151-9.

35. Zahm SH, Hoffman-Goetz L, Dosemeci M, Cantor KP, Blair A. Occupational physical activity and non-Hodgkin's lymphoma. Med Sci Sports Exerc. 1999; 31(4):566-71.

36. Linet MS, Vajdic CM, Morton LM, De Roos AJ, Skibola CF, Boffetta P, et al. Medical history, lifestyle, family history, and occupational risk factors for follicular lymphoma: The interlymph non-hodgkin lymphoma subtypes project; 2014. p. 26-40

37. Morton LM, Slager SL, Cerhan JR, Wang SS, Vajdic CM, Skibola CF, et al. Etiologic heterogeneity among non-hodgkin lymphoma subtypes: The interlymph non-hodgkin lymphoma subtypes project; 2014. p. 130-44

38. Aschebrook-Kilfoy B, Cocco P, La Vecchia C, Chang ET, Vajdic CM, Kadin ME, et al. Medical history, lifestyle, family history, and occupational risk factors for mycosis fungoides and Sezary syndrome: the InterLymph non-Hodgkin lymphoma subtypes project. J Natl Cancer Inst Monogr. 2014;2014(48):98105.

39. Vajdic CM, Landgren O, McMaster ML, Slager SL, Brooks-Wilson A, Smith A, et al. Medical history, lifestyle, family history, and occupational risk factors for lymphoplasmacytic lymphoma/Waldenström's macroglobulinemia: The InterLymph non-Hodgkin lymphoma subtypes project; 2014. p. 87-97.

40. Moore SC, Lee IM, Weiderpass E, Campbell PT, Sampson JN, Kitahara CM, et al. Association of Leisure-Time Physical Activity with Risk of 26 types of Cancer in 1.44 million adults. JAMA Intern Med. 2016;176(6):816-25.

41. Boyle T, Keegel T, Bull F, Heyworth J, Fritschi L. Physical activity and risks of proximal and distal colon cancers: a systematic review and meta-analysis. J Natl Cancer Inst. 2012;104(20):1548-61.

42. Neilson HK, Farris MS, Stone CR, Vaska MM, Brenner DR, Friedenreich CM. Moderate-vigorous recreational physical activity and breast cancer risk, stratified by menopause status: a systematic review and meta-analysis. Menopause. 2017;24(3):322-44.

43. Schmid D, Behrens G, Keimling M, Jochem C, Ricci C, Leitzmann M. A systematic review and meta-analysis of physical activity and endometrial cancer risk. Eur J Epidemiol. 2015;30(5):397-412.

44. Psaltopoulou T, Ntanasis-Stathopoulos I, Tzanninis IG, Kantzanou M, Georgiadou D, Sergentanis TN. Physical activity and gastric Cancer risk: a systematic review and Meta-analysis. Clin J Sport Med. 2016;26(6):445-64.

45. Ntanasis-Stathopoulos J, Tzanninis JG, Philippou A, Koutsilieris M. Epigenetic regulation on gene expression induced by physical exercise. J Musculoskelet Neuronal Interact. 2013;13(2):133-46.

46. Pan SY, DesMeules M. Energy intake, physical activity, energy balance, and cancer: epidemiologic evidence. Methods Mol Biol. 2009;472:191-215.

47. World Health Organization. WHO | Physical Activity and Adults: World Health Organization; 2015 [updated 2015-06-19 13:45:03. Available from: https://www.who.int/dietphysicalactivity/factsheet_adults/en/.

48. Ren JS, Kamangar F, Forman D, Islami F. Pickled food and risk of gastric cancer--a systematic review and meta-analysis of English and Chinese literature. Cancer Epidemiol Biomark Prev. 2012;21(6):905-15.

\section{Publisher's Note}

Springer Nature remains neutral with regard to jurisdictional claims in published maps and institutional affiliations.

\section{Ready to submit your research? Choose BMC and benefit from}

- fast, convenient online submission

- thorough peer review by experienced researchers in your field

- rapid publication on acceptance

- support for research data, including large and complex data types

- gold Open Access which fosters wider collaboration and increased citations

- maximum visibility for your research: over $100 \mathrm{M}$ website views per year

At BMC, research is always in progress.

Learn more biomedcentral.com/submissions 